\title{
Identification of Intracellular Factor XIII in Human Monocytes and Macrophages
}

Per Henriksson, Susanne Becker, Garny Lynch, and Jan McDonagh

Department of Pediatrics, and Blood Coagulation Laboratory, University of Lund, General Hospital, Malmö, Sweden;

Department of Obstetrics and Gynecology, University of North Carolina, Chapel Hill, North Carolina 27514; Department of Pathology,

Beth Israel Hospital and Harvard Medical School, and Charles A. Dana Research Institute, Boston, Massachusetts 02215

\begin{abstract}
Factor XIII is a blood protransglutaminase that is distributed in plasma and platelets. The extracellular and intracellular zymogenic forms differ in that the plasma zymogen contains $A$ and $B$ subunits, while the platelet zymogen has $A$ subunits only. Both zymogens form the same enzyme. Erythrocytes, in contrast, contain a tissue transglutaminase that is distinct from Factor XIII. In this study other bone marrow-derived cells were examined for transglutaminase activity. Criteria that were used to differentiate Factor XIII proteins from erythrocyte transglutaminase included: (a) immunochemical and immunohistochemical identification with monospecific polyclonal and monoclonal antibodies to Factor XIII proteins, (b) requirement for thrombin cleavage to express activity, (c) pattern of fibrin cross-linking catalyzed by the enzyme, and $(d)$ different electrophoretic mobilities in nondenaturing gel systems. By these criteria human peripheral blood monocytes, peritoneal macrophages, and monocytes maintained in culture contain an intracellular protransglutaminase that is the same as platelet Factor XIII. The monocyte-macrophage protein is thrombin-sensitive, and under appropriate conditions there is no enzyme expression without activation of the zymogen. Both the monocyte-macrophage zymogen and enzyme have the same electrophoretic mobilities as platelet Factor XIII zymogen and enzyme. Antibody to $A$ protein reacts with the monocyte-macrophage protein. $B$ protein is not associated with this intracellular zymogen. By immunoperoxidase staining monocyte-macrophage protein seems to be localized in the cytoplasm, similar to the known cytoplasmic distribution of platelet and megakaryocyte Factor XIII. These procedures were also used to study populations of human granulocytes and lymphocytes, and protransglutaminase activity was not observed in these cells.
\end{abstract}

\section{Introduction}

Transglutaminases constitute a class of widely dispersed, $\mathrm{Ca}^{2+}$ dependent enzymes that catalyze an acyl transfer reaction between the $\gamma$-carboxamide group of a peptide-bound glutamine residue and various primary amines. Several distinct types of

Portions of this work were presented at the American Heart Association meeting, Dallas, TX, November 1982; and have been published in abstract form, 1982. Circulation. 66:320.

Address correspondence to Dr. McDonagh, Department of Pathology, Beth Israel Hospital, Boston, MA 02215.

Received for publication 21 March 1984 and in revised form 18 April 1985.

J. Clin. Invest.

(C) The American Society for Clinical Investigation, Inc.

0021-9738/85/08/0528/07 \$1.00

Volume 76, August 1985, 528-534 transglutaminases have been identified, of which the most well characterized are tissue transglutaminase and Factor XIIIa. A tissue transglutaminase, which may be present in many cell types, is usually isolated from liver or erythrocytes (1). It is a monomeric protein (relative molecular weight $\left[M_{\mathrm{r}}\right]^{1} \sim 75,000$ 80,000 ) which has only been detected as an active enzyme; no zymogen has been found (2-4). Factor XIIIa, the blood coagulation enzyme that was first found to catalyze the covalent stabilization of fibrin, exists in two zymogenic forms. Extracellular or plasma Factor XIII is a noncovalently associated tetramer $\left(M_{\mathrm{r}} \sim 320,000\right)$, consisting of two $\mathrm{A}$ and two $\mathrm{B}$ subunits; intracellular Factor XIII is a dimer $\left(M_{r} \sim 150,000\right)$ of $\mathrm{A}$ subunits. The $\mathrm{A}$ chains in both zymogens are identical $\left(M_{\mathrm{r}} \sim 75,000\right)(5)$. With activation, both zymogens give rise to the same enzymatic activity. Intracellular Factor XIII has been identified in platelets, megakaryocytes, placenta, and uterus $(6,7)$.

Transglutaminase activity can be monitored by the covalent incorporation of a suitable primary amine, usually a lysine analogue such as dansylcadaverine or putrescine, into a peptidebound acceptor glutamine residue $(8,9)$. Factor XIIIa activity can be differentiated from tissue transglutaminase by the requirement for activation of the Factor XIII zymogen to expose the active center cysteine. This is usually achieved by thrombin cleavage of the A protein in the presence of calcium ions (10). Other in vitro mechanisms for zymogen activation include high concentration of calcium alone or calcium plus thiocyanate (11-13). Tissue transglutaminase is immunochemically distinct from platelet and plasma Factor XIII. The tissue protein and the Factor XIII proteins also have different electrophoretic mobilities in nondenaturing gel systems $(14,15)$.

Using an assay based on the incorporation of $\left[{ }^{14} \mathrm{C}\right]$ putrescine into $N, N^{\prime}$-dimethylcasein, Novogrodsky et al. (16) identified transglutaminase activity in human peripheral blood lymphocytes and macrophages and also found that enzyme activity in lymphocytes, but not in macrophages, was enhanced by prior incubation of the cells with high concentrations of concanavalin $A$ and phytohemagglutinin. Schroff et al. (17) used fluorescent staining of cells with dansylcadaverine and incorporation of $\left[{ }^{14} \mathrm{C}\right]$ putrescine into $\alpha$-casein by cell homogenates to detect transglutaminase activity in murine macrophages. In this study monocytes were negative and so also were lymphocytes, with or without concanavalin A stimulation. Transglutaminase activity has also been detected in murine leukemia M1 cells during the course of differentiation into mature, macrophagelike $\mathrm{M}^{+}$cells (18). Murtaugh et al. (19) observed high levels of transglutaminase in mouse peritoneal macrophages that had been cultured in mouse plasma or serum. This activity was not enhanced by lipopolysaccharide activation of the macrophages. However, Murtaugh et al. (20) also found that transglutaminase activity of human monocytes in culture increased

1. Abbreviations used in this paper: $M_{\mathrm{r}}$, relative molecular weight. 
with lipopolysaccharide stimulation. In these studies it was concluded that the enzyme detected was tissue transglutaminase.

We have used monoclonal and polyclonal antibodies to Factor XIII proteins, activity measurements, and electrophoretic mobility in a nondenaturing system, to characterize transglutaminase activity in human monocytes and macrophages. These studies show that monocytes and macrophages contain a zymogen identical to intracellular or platelet Factor XIII. This zymogen is immunochemically identical to the A protein of Factor XIII; it also has the same activation requirement and electrophoretic mobility. We have not observed transglutaminase activity in granulocytes or lymphocytes.

\section{Methods}

Cell preparations. Macrophages were isolated from peritoneal fluid obtained from healthy women undergoing laparoscopic bilateral tubal ligation or from patients with endometriosis. Peritoneal fluid was aspirated under direct visual control through a catheter (Silastic Medical Products, Dow Corning Corp., Midland, MI); it was placed in tubes containing heparin and was centrifuged at $300 \mathrm{~g}$ for $5 \mathrm{~min}$. If the fluid contained an excess of erythrocytes, it was underlayered with FicollHypaque (LSM Litton Bionetics, Kensington, MD) and centrifuged at $400 \mathrm{~g}$ for $10 \mathrm{~min}$. The cells were washed three times in cold RPMI 1640 medium. With this procedure macrophages composed $85-99 \%$ of the nucleated cells.

Mononuclear cells from healthy blood donors were isolated on Ficoll-Hypaque gradients (21). Minimal platelet contamination of the mononuclear cell fraction (one platelet per 100 mononuclear cells) was obtained by centrifuging the cells through human serum at room temperature at $300 \mathrm{~g}$ for $10 \mathrm{~min}$. By light microscopy no platelets were seen adhering to the monocytes. Monocytes were separated from lymphocytes by adherence to Petri dishes coated with human serum for $45 \mathrm{~min}$ at $37^{\circ} \mathrm{C}$ and in $5 \% \mathrm{CO}_{2}$. Nonadherent lymphocytes were then removed by vigorous washing. The $98-99 \%$ pure monocyte population was detached from the plates by exposure to ice-cold Versene 1:5,000 (Gibco Laboratories, Grand Island, NY) for $5 \mathrm{~min}$.

Granulocytes were obtained by suspending the pellet from the Ficoll-Hypaque gradient with dextran (22).

Monocytes and macrophages were identified on cytocentrifuge preparations by morphology, nonspecific esterase stain (23), and by phagocytosis of opsonized zymosan particles. Monocyte cultures were established from mononuclear cells adjusted to $4 \times 10^{6} / \mathrm{ml}$. Cells were plated in 16- $\mathrm{mm}$ wells, and after $45 \mathrm{~min}$ nonadherent cells were removed by vigorous washing. Monocytes were cultured in Eagle's minimal essential medium-alpha with $5 \% \mathrm{AB}^{+}$serum and antibiotics at $37^{\circ} \mathrm{C}$ and $5 \% \mathrm{CO}_{2}$. These culture conditions led to maturation of monocytes to macrophages, as indicated by increased cell size, spreading, phagocytic activity, and lysosomal enzyme content. Monocytes-macrophages were harvested at various times in culture by first detaching them with ice-cold Versene 1:5,000. Culture medium was concentrated with a Diaflo PM30 ultrafilter (Amicon Corp., Danvers, MA), with a membrane retentivity exceeding a molecular weight of 30,000 .

Erythrocytes were isolated from citrated blood and washed with isotonic buffer. Packed cells were stored at $-80^{\circ} \mathrm{C}$ and thawed quickly at $37^{\circ} \mathrm{C}$ immediately before use.

Cell extracts. Mononuclear cells were suspended at $\sim 10^{6} / \mathrm{ml}$ in RPMI 1640 and were centrifuged at $1,100 \mathrm{~g}$ for $10 \mathrm{~min}$ at $4^{\circ} \mathrm{C}$. Cell pellets were resuspended in $0.01 \mathrm{M}$ Tris, $0.1 \mathrm{M} \mathrm{NaCl}, 0.001 \mathrm{M}$ EDTA, pH 7.5. Two procedures were used to lyse the cells. In some experiments $0.5 \%$ Triton X-100 was incorporated into the buffer, and the cells were incubated for $45 \mathrm{~min}$ at $4^{\circ} \mathrm{C}$. In other experiments the cells were suspended in buffer without Triton X-100 and disrupted in an Omnimixer (Sorvall, Newtown, CT) with five 30 -s bursts at $4^{\circ} \mathrm{C}$. Both procedures gave the same results. Lysed cells were centrifuged at $10,000 \mathrm{~g}$ for $20 \mathrm{~min}$. Throughout the procedure the cells and cell lysates were kept at $4^{\circ} \mathrm{C}$; and after the final centrifugation, the supernatant was removed and assayed immediately for Factor XIII activity.

Erythrocytes were disrupted in a tissue homogenizer in buffer containing $2 \mathrm{mM}$ EDTA and were otherwise treated similarly to the mononuclear cells.

Protein concentration of cell extracts was determined with the protein assay from Bio-Rad Laboratories, Richmond, CA, with bovine albumin as the standard. Samples containing Triton X-100 were corrected for the presence of detergent.

Activity measurement. Factor XIII activity was quantitated by incorporating monodansylcadaverine (Sigma Chemical Co., St. Louis, $\mathrm{MO}$ ) into casein (8). The complete assay system included preincubation of test material with thrombin and $\mathrm{CaCl}_{2}$ to activate the zymogen. Test samples were also assayed without thrombin and $\mathrm{CaCl}_{2}$ activation and with thrombin alone and $\mathrm{CaCl}_{2}$ alone. In all cases $\mathrm{CaCl}_{2}$ was present in the incorporation phase. Pooled normal, platelet-poor plasma and preparations of purified plasma Factor XIII (24) and platelet Factor XIII (25) were used as controls for all studies. This assay can detect $\sim 10-15 \mathrm{ng}$ of $A$ protein activity.

Assessment of electrophoretic mobility, based on activity detection, was made by activity staining of the gel, after electrophoresis under nondenaturing conditions (14). Agarose gel electrophoresis was performed at $10^{\circ} \mathrm{C}$ at $18-20 \mathrm{~V} / \mathrm{cm}$ in $1-\mathrm{mm}$ thick gels containing $0.8 \%$ agarose (Seakem, Springfield, NJ), on GelBond NF supports. Samples were subjected to electrophoresis in 0.1 M Barbital I (Bio-Rad Laboratories), $\mathrm{pH} 8.6$, containing $2 \mathrm{mM}$ EDTA. Factor XIII activity was visualized by staining the electropherograms at $37^{\circ} \mathrm{C}$ for $90 \mathrm{~min}$ with a solution containing $10 \mathrm{IU} / \mathrm{ml}$ bovine thrombin (Parke-Davis), 35 $\mathrm{mM} \mathrm{CaCl}, 2 \mathrm{mM}$ dithiothreitol, $0.7 \mathrm{mM}$ monodansylthiacadaverine (Larodan Fine Chemicals, Malmö, Sweden), and 1.0\% casein Hammarsten (ICN K \& K Laboratories, Inc., Plainview, NY) in $50 \mathrm{mM}$ Tris-HCl, pH 7.5. In some experiments thrombin or $\mathrm{CaCl}_{2}$ was omitted from the staining solution. Purified plasma and platelet Factor XIII and erythrocyte transglutaminase were used as electrophoretic mobility markers for the various types of transglutaminases. After incubation in the staining solution, gels were immersed in $10 \%$ trichloroacetic acid for $20 \mathrm{~min}$, washed repeatedly in $10 \%$ acetic acid, and then neutralized in $50 \mathrm{mM}$ Tris- $\mathrm{HCl}$, pH 7.5. Fluorescent bands were readily visualized in ultraviolet light, and they were photographed through a Wratten No. 15 filter. This procedure can detect $<0.9 \mathrm{nM}$ Factor XIII activity.

Immunochemical characterization. Both monoclonal and polyclonal antibodies to Factor XIII proteins were used. Monoclonal antibodies were prepared by immunizing with purified preparations of $A$ and $B$ proteins. Positive clones were subcloned in soft agar two or three times (26). Monoclonal antibodies were characterized with respect to immunoglobulin class, ability to bind the various molecular forms of Factor XIII proteins, and ability to inhibit Factor XIII activation or activity. Monoclonal antibodies to $A$ protein and to $B$ protein were used for immunoblotting $(27,28)$, after electrophoresis of samples in 6\% sodium dodecyl sulfate (SDS) polyacrylamide gels (29).

Monospecific rabbit antisera were used to detect Factor XIII in all extracts by crossed immunoelectrophoresis (30). It had previously been determined that anti-A reacted only with $A$ and not $B$, and anti-B reacted only with $B$ and not $A(31,32)$. These antisera did not react with tissue transglutaminase.

Both monoclonal and polyclonal antibodies were used for immunohistochemical examination of cells by the immunoperoxidase method $(33,34)$, using the Vectastain ABC Reagent (Vector Laboratories, Inc., Burlingame, CA). Cytocentrifuge preparations were fixed in methanol/ acetone $(50: 50)$ or calcium acetate formalin before staining.

Fibrin cross-linking. To assess the substrate specificity of monocytemacrophage transglutaminase, fibrin gels were cross-linked with activated macrophage transglutaminase, and the cross-linking pattern was determined by reduced SDS gel electrophoresis (35). In some experiments fibrinogen pretreated with $p$-chloromercuribenzoate to inactivate all traces of contaminating Factor XIII (36) was used as substrate. In other experiments plasma from a patient with homozygous Factor 
XIII deficiency ( $<1 \%$ Factor XIII) was used. With both test systems, a trace amount of ${ }^{125}$ I-fibrinogen (37) was added. After electrophoresis, autoradiograms were prepared.

\section{Results}

Transglutaminase activity in blood cells was initially characterized by electrophoretic mobility in nondenaturing, nonreducing buffer, with in situ demonstration of enzymatic activity. Fig. 1 shows the presence of transglutaminase activity in cell lysates prepared from peritoneal fluid macrophages (lane 1), peripheral blood monocytes (lanes 4, 5), platelets (lane 6), and erythrocytes (lane 8), with plasma Factor XIII (lane 7), as control. The known mobility difference in this gel system between plasma and platelet Factor XIII versus erythrocyte (tissue) transglutaminase is apparent. It can be seen that the activity observed in the monocyte-macrophage lysates migrated with platelet and plasma Factor XIII. Granulocytes and lymphocytes, obtained from normal donors, were found to be negative (lanes 2, 3). For these experiments any remaining contaminating monocytes were separated out by allowing the cells to ingest iron particles for $1 \mathrm{~h}$ at $37^{\circ} \mathrm{C}$ and then removing them with a magnet. In some experiments lymphocytes were very faintly positive, which may have been due to failure to remove all contaminating monocytes from the lymphocyte preparation.

The requirement for activation of macrophage protransglutaminase is demonstrated in Fig. 2 with cell extracts of peritoneal macrophages from three patients. Electrophoresis of cell extracts and plasma was done without preactivation, and then half of the gel was stained for transglutaminase with thrombin activation and the other half without thrombin. As would be expected, Factor XIII activity was observed in the plasma sample that was thrombin activated (lane 1) but not in the unactivated sample (lane 8). Identical results were obtained with the three macrophage samples. When macrophage samples were rapidly and carefully processed from freshly obtained cells, transglutaminase activity was consistently not observed by activity staining of electropherograms in the absence of thrombin at the $\mathrm{CaCl}_{2}$ concentration used. The converse was also true; no transglutaminase activity was observed in plasma or in macrophage extracts when the gels were stained with a solution containing thrombin but no $\mathrm{CaCl}_{2}$. Expression of activity in macrophages, as in plasma,

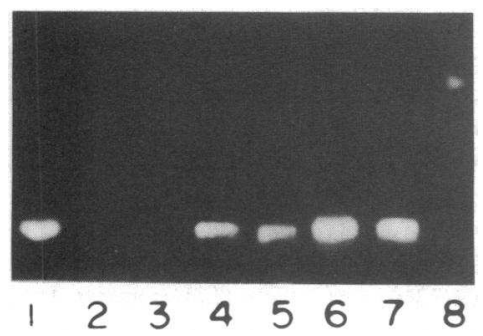

Figure 1. Electrophoresis and activity staining for the detection of transglutaminase activity in cell lysates of human peritoneal macrophages and peripheral blood cells. Agarose electrophoresis in barbital buffer was performed at $10-12 \mathrm{~V} / \mathrm{cm}$ at $10^{\circ} \mathrm{C}$ for $\sim 90 \mathrm{~min}$ on

samples of freshly prepared extracts. Staining solution for visualization of enzymatic activity contained thrombin, $\mathrm{CaCl}_{2}$, monodansylthiacadaverine, dithiothreitol, and casein. Cell extracts are from: 1 , peritoneal fluid macrophages $\left(2 \times 10^{6}\right.$ cells $\left./ 100 \mu \mathrm{l}\right) ; 2$, granulocytes $\left(2 \times 10^{6} / 100 \mu \mathrm{l}\right) ; 3$, lymphocytes $\left(1.7 \times 10^{6} / 100 \mu \mathrm{l}\right) ; 4$ and 5 , monocytes $\left(2 \times 10^{6} / 100 \mu \mathrm{l}\right) ; 6$, platelets $\left(2 \times 10^{6} / 100 \mu \mathrm{l}\right) ; 7$, plasma control; 8 , erythrocytes $\left(2 \times 10^{6} / 100 \mu \mathrm{l}\right)$.

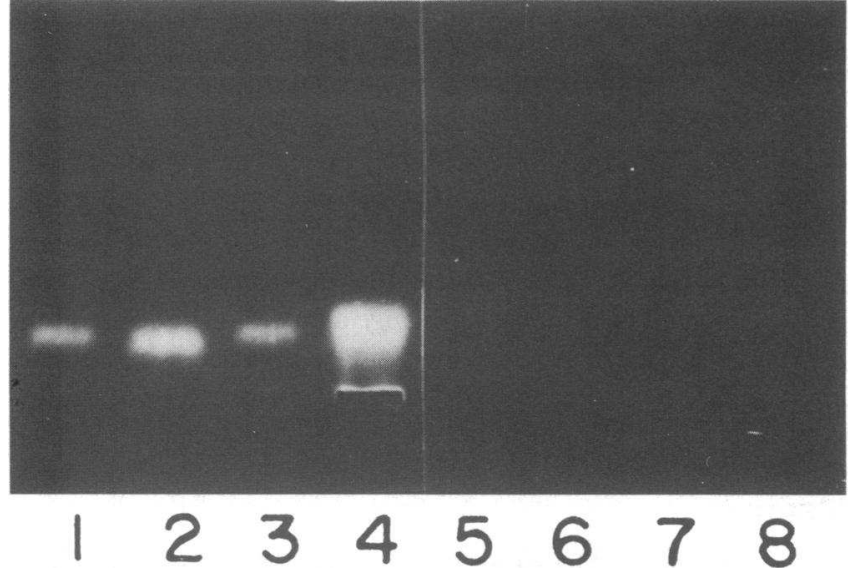

Figure 2. Demonstration of thrombin activation of macrophage transglutaminase. Samples were examined by agarose electrophoresis in barbital buffer under nondenaturing, nonreducing conditions. After electrophoresis the plate was divided in half for activity staining. Lanes 1-4 were developed with staining solution containing thrombin (as in Fig. 1), and lanes 5-8 were stained with the same solution except that thrombin was omitted. Samples: plasma Factor XIII (control) in lanes 1 and 8 and macrophage cell lysates from three patients (lanes 2-4 and 5-7).

required complete activation, in this case, with thrombin and $\mathrm{CaCl}_{2}$. However, it should be noted that transglutaminase activity could be readily generated during storage of cells and cell lysates, and it was only fresh extracts that were consistently negative. We have also observed similar activation of platelet Factor XIII in stored, lysed platelets and in placental extracts.

Direct experiments were also performed to quantitate the transglutaminase activity in monocyte and macrophage lysates by means of the dansylcadaverine incorporation assay. In this assay, also, activity was not observed in fresh cell extracts unless the samples were treated with thrombin. With the complete activation system, the transglutaminase activity of three monocyte preparations was measured in the soluble fraction from $10^{6}$ cells. The values were $0.10,0.18$, and 0.25 $\mu \mathrm{mol}$ dansylcadaverine incorporation per $20 \mathrm{~min}$ incorporation time. With four peritoneal fluid macrophage preparations, the values were $0.15,0.23,0.38$, and $1.41 \mu \mathrm{mol} / 10^{6}$ cells per 20 min. Granulocyte and lymphocyte cell lysates were also assayed in the dansylcadaverine incorporation assay and were found to be negative.

Further experiments were performed to characterize monocyte-macrophage protransglutaminase immunochemically. Fig. 3 shows an immunoblot of purified platelet Factor XIII (lanes 1 and 2) and macrophage cell lysate (lanes 3 and 4), which was developed with monoclonal antibody to A protein. Lanes 1 and 3 contain untreated samples and lanes 2 and 4 contain material preincubated with thrombin. It can be seen that the monoclonal antibody recognizes a protein in the macrophage cell lysate (lane 3 ) with a mobility identical to platelet $A$ protein (lane 1). Furthermore, after partial activation with thrombin, both the $\mathrm{A}$ and cleaved $\mathrm{A}$ bands are visible in the macrophage preparation (lane 4). In similar experiments in which the transblot was stained with monoclonal anti-B, no bands were visualized, indicating the absence of $B$ protein both in platelet-Factor XIII and in the macrophage cell lysate.

Crossed immunoelectrophoresis was used to characterize 


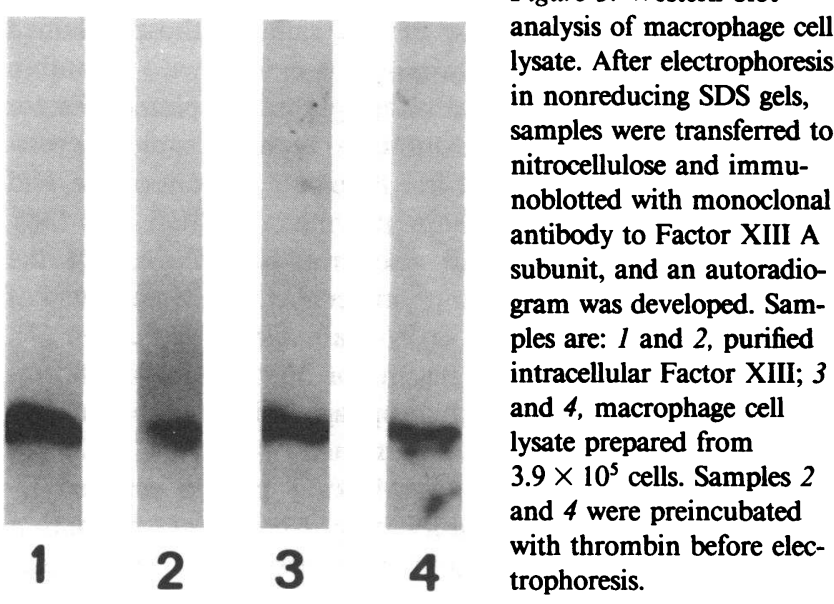

monocyte-macrophage lysates further. On crossed immunoelectrophoresis with polyclonal anti-A, extracts from cultured monocytes and from peritoneal fluid macrophages formed precipitin arcs, which were the same as that formed with plasma or platelet Factor XIII. Analysis of B protein was carried out by electrophoresis of duplicate samples in agarose containing anti-B serum and then developing the precipitin arc in one sample with activity stain for $A$ and the other sample with protein stain. If the test material contains plasma Factor XIII $\left(A_{2} B_{2}\right)$, activity stain will visualize a precipitin arc that is coincident with the $B$ protein arc. If the sample contains A but not B protein the activity stain will visualize a diffuse spot which is not related to any precipitin arc. Fig. 4 shows the results of this experiment. When purified $A_{2} B_{2}$ was tested, activity staining revealed a fluorescent arc which was in the same position as the $B$ protein arc, indicating coelectrophoresis of the $A$ and $B$ proteins in the plasma zymogen complex (sample 3). When excess $A$ protein was added to $A_{2} B_{2}$, both a fluorescent arc and a diffuse fluorescent spot above it were observed, indicating the presence of uncomplexed $A$ protein (sample 2). When macrophage extract was tested under the same conditions, only a diffuse activity spot was observed, which was in the same position as the spot for free A protein (sample 1). Protein stain of the macrophage extract for B did not visualize any arc. These results also indicate that macrophage extracts contain a protein with potential transglutaminase

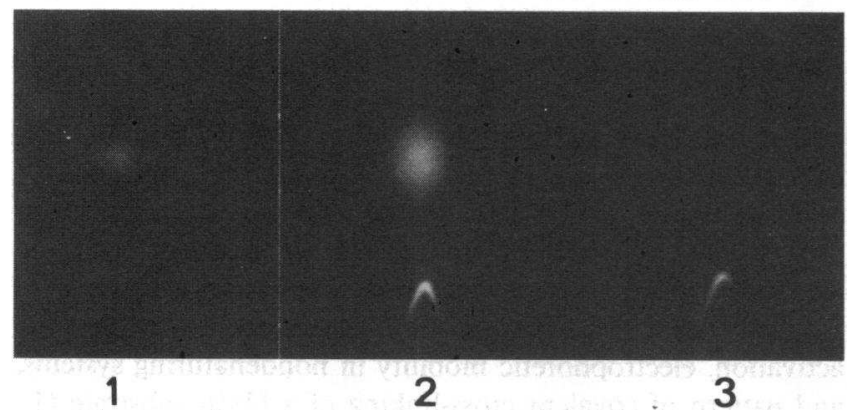

Figure 4. Crossed immunoelectrophoresis with antiserum to Factor XIII B subunit and activity staining to visualize A subunit, as described in Methods. Samples are: 1, macrophage extract; 2, purified plasma Factor XIII with purified platelet Factor XIII added; 3, purified plasma Factor XIII. activity which is immunochemically identical to the A protein of Factor XIII. There is no evidence for B protein in macrophages.

Immunoperoxidase staining was used to localize A protein in monocytes and macrophages. Fig. 5 shows the appearance of cells in culture for $6 \mathrm{~d}$, which were stained with monoclonal antibody to A protein. Positive staining was seen throughout the cytoplasm in a diffuse, lace-like pattern. There was no specific staining of the plasma membrane, nucleus, or other subcellular organelles. Staining was not observed with an irrelevant monoclonal antibody. Identical results were obtained with polyclonal anti-A, which also showed diffuse, cytoplasmic staining. Anti-A serum, blocked with purified A protein, was negative. Cytocentrifuge preparations of peripheral blood mononuclear cell fraction were also stained with monoclonal antibody to A protein. Platelets and monocytes were clearly positive, while lymphocytes were negative.

Factor XIII-deficient plasma, to which a trace amount of ${ }^{125}$ I-fibrinogen was added, was clotted with thrombin and $\mathrm{CaCl}_{2}$, with and without an added source of Factor XIII. The clot was then washed and solubilized in urea-SDS-dithiothreitol buffer, and the covalent cross-linking pattern was assessed by gel electrophoresis and autoradiography (Fig. 6). The control sample, with only buffer added, showed the typical reduced SDS gel pattern of noncross-linked fibrin, that is, $\gamma, \beta$, and $\alpha$ chains, with no $\gamma$-dimer or $\alpha$-polymer. Samples to which purified plasma Factor XIII or monocyte/macrophage cell lysate was added contained cross-linked $\gamma$-dimer and $\alpha$-polymer, as well as some uncross-linked $\alpha$-chain and free $\beta$-chain. The same results were obtained when Factor XIII-free fibrinogen was used as the substrate.

Transglutaminase activity was also measured in monocytes in culture. Cell extracts prepared from $10^{6}$ fresh monocytes, when assayed after thrombin and $\mathrm{CaCl}_{2}$ activation, catalyzed the incorporation of $1.83 \pm 0.60 \mathrm{nmol}$ dansylcadaverine per $\mu \mathrm{g}$ protein. For day 3-4 monocytes and day 5-6 monocytes in culture the comparable values were $0.96 \pm 0.08$ and $1.77 \pm 0.32$ nmol dansylcadaverine incorporation per $\mu \mathrm{g}$ protein. These data indicate that although protransglutaminase increased over

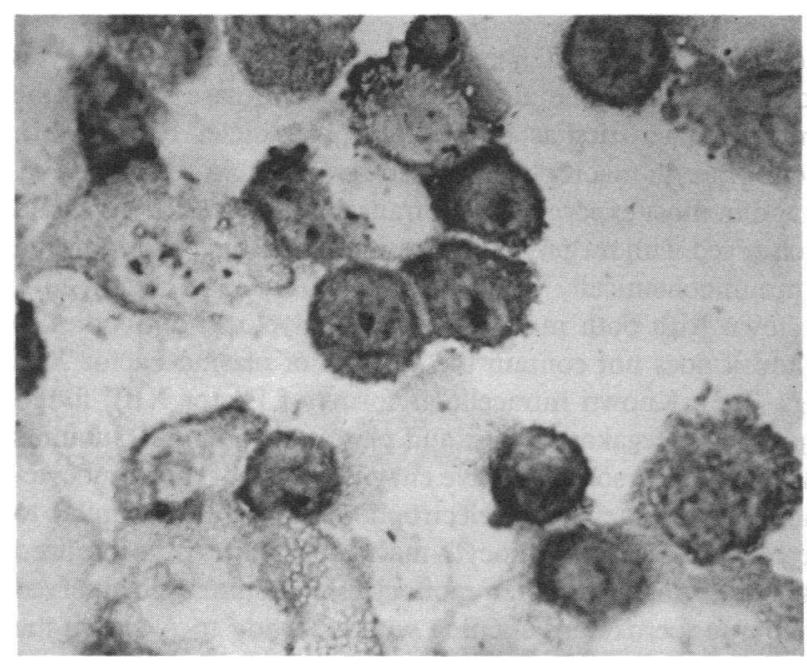

Figure 5. Immunoperoxidase staining of monocytes which had been cultured for $6 \mathrm{~d}$ as described in Methods. After washing and fixation the cells were reacted with monoclonal antibody to the A protein. 


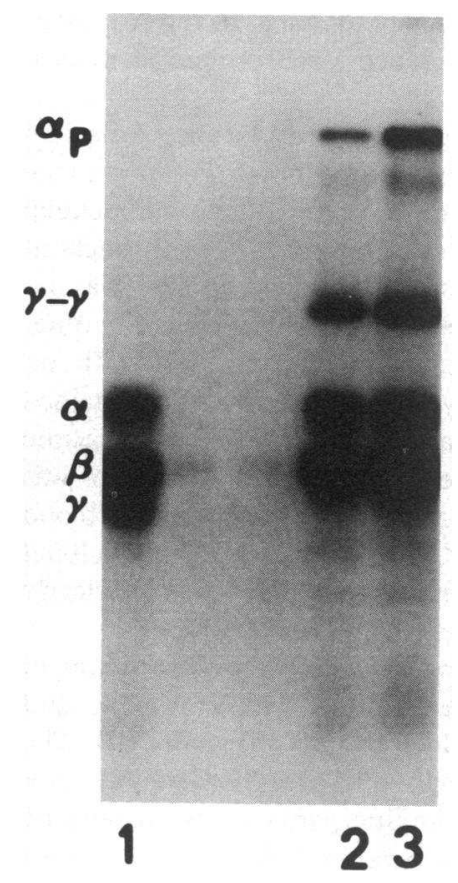

Figure 6. Pattern of fibrin cross-linking catalyzed by macrophage enzyme. Factor XIIIdeficient plasma, to which a trace of ${ }^{125}$ I-fibrinogen was added, was clotted with thrombin and $\mathrm{CaCl}_{2}$ and either purified Factor XIII or macrophage cell lysate. Clots were washed, subjected to reduced SDS electrophoresis, and an autoradiogram was prepared. Lane 1 , control (no Factor XIII or other source of transglutaminase) showing pattern of noncross-linked fibrin; lane 2, cross-linked fibrin formed with added Factor XIII; lane 3, cross-linked fibrin formed with macrophage lysate.

the 7-d culture period, it remained constant with respect to total protein. From our measurements of activity and protein, both with purified preparations and also in plasma, we can calculate the specific activity of Factor XIII to be 1.5-2.0 $\mu \mathrm{mol}$ of dansylcadaverine incorporation per $30 \mathrm{~min}$ per $\mu \mathrm{g}$ of $\mathrm{A}$ protein. On this basis A protein comprises $\sim 1 \mathrm{ng}$ per $\mu \mathrm{g}$ of total cytoplasmic protein in the cultured monocytes. 24-h and 72-h conditioned media were also tested and were found to be no different from fresh medium. The small amount of activity in the medium was due to the presence of activated Factor XIII in the serum added to the medium. Thus, under the culture conditions used, protransglutaminase was not secreted into the culture medium.

\section{Discussion}

The results presented here indicate that human monocytes and macrophages contain a protransglutaminase that has the same characteristics as intracellular or platelet Factor XIII. The monocyte-macrophage protein is thrombin-sensitive (Fig. 2), and in most experiments no transglutaminase activity could be observed without pretreatment with thrombin. The zymogen is immunochemically identical to the A chain of Factor XIII, as shown with both monoclonal and polyclonal antibodies to A; and it does not contain the B chain of plasma Factor XIII (Figs. 3-5). Known intracellular forms of Factor XIII, found in platelets, megakaryocytes, and placenta, contain A subunits only. The precursor and active enzyme forms of the monocytemacrophage protein have electrophoretic mobilities similar to Factor XIII (Fig. 1). Monocyte-macrophage protein is localized in the cell cytoplasm. When monocytes in culture were observed by immunoperoxidase staining with antibody to A chain, the cytoplasm was positive but there was no staining associated with the plasma membrane or subcellular organelles. By immunofluorescence platelet and megakaryocyte Factor XIII were previously found to be cytoplasmic constituents (6).
The fibrin cross-linking reactions catalyzed by monocytemacrophage transglutaminase are the same as those obtained with Factor XIIIa. When fibrinogen is clotted with thrombin and $\mathrm{CaCl}_{2}$ in the presence of either plasma or platelet Factor XIII, the resulting fibrin exhibits a typical covalent crosslinking pattern, composed of free $\beta$-chains, $\gamma$-chain dimer, and high molecular weight $\alpha$-chain polymer, on SDS gels (38). Tissue transglutaminase will also cross-link fibrin, but the cross-linking pattern shows high molecular weight polymers of $\alpha$-chains and $\gamma$-chains and no $\gamma$-chain dimer formation (7). When Factor XIII-deficient plasma or Factor XIII-free fibrinogen was clotted with the macrophage soluble fraction, and the clot was solubilized and examined by reduced SDS gel electrophoresis, the fibrin cross-linking pattern showed $\gamma$ dimer and $\alpha$-polymer formation (Fig. 6). $\gamma$-dimer formation differentiates Factor XIIIa activity from tissue transglutaminase, since $\gamma$-dimers are not observed with the tissue enzyme (7).

The possibility that monocytes-macrophages absorbed A chain from plasma or serum is unlikely. Plasma A chain forms a tight noncovalent complex with $B$ chain; and there is no evidence for free, uncomplexed $A$ chain in plasma, either in the precursor or active enzyme forms. We have also not been able to find free B chain in plasma (32). It seems improbable, therefore, that monocytes selectively absorb A chain, leaving $B$ chain behind in plasma. Serum contains a small amount of A chain, which is all in the active enzyme form (32). Hence, this is not the source of A chain for the monocytes in culture. In addition, cells cultured in serum-free medium also contain protransglutaminase.

Additional support for the identification of $A$ protein in monocytes is also provided by our recent studies with the human monocyte-macrophage cell line, U937. These cells stain with antibodies to A protein but not B protein, and the cell cytosol contains a protransglutaminase which is thrombin sensitive. When the cells are maintained in culture for $48 \mathrm{~h}$ in serum-free medium, no protransglutaminase activity can be detected in the cytosol without thrombin activation (39). The results presented thus indicate that human monocytes and macrophages contain a cytoplasmic protein with potential transglutaminase activity, which is identical to the A protein of plasma and platelet Factor XIII. This conclusion is based on immunochemical identification, activation requirements, electrophoretic mobility, and fibrin cross-linking pattern of the monocyte-macrophage protein.

It should be noted that other investigators (16-20), working with both murine and human monocytes and macrophages, have identified transglutaminase activity in these cells with apparently different characteristics from those described here and have identified the enzyme as tissue transglutaminase. It is not entirely clear how the present and previous studies should be reconciled. By definition tissue transglutaminases are a group of related intracellular enzymes with molecular weight of $\sim 75,000-80,000$ which can be differentiated from the Factor XIIIa type of transglutaminases on the basis of immunochemical characterization, requirement for zymogen activation, electrophoretic mobility in nondenaturing systems, and pattern of covalent cross-linking of a fibrin substrate (1$3,7)$. Importantly, there is thought to be no immunochemical cross-reactivity between the tissue-type and Factor XIII-type proteins (7). However, differentiation may be difficult.

In other studies, for example, transglutaminase activity was detected in assay systems that did not employ thrombin, 
implying that the active enzyme was present in the cells. However, our experience with platelet and placental Factor XIII, as well as monocyte and macrophage extracts, indicates that zymogen activation may occur readily in cell lysates. Factor XIII in platelet or placental extracts will readily undergo conversion to enzyme if it is not rapidly and carefully separated from the cytosol. There is evidence that cathepsin $\mathrm{C}$ or catheptic carboxypeptidase can activate intracellular Factor XIII, and this activation is facilitated by $\mathrm{CaCl}_{2}$ and reducing agents (Lynch, G., and S. Pfueller, unpublished observations). This may also be a pathway for activation of monocytemacrophage Factor XIII. Another possible mechanism might involve $\mathrm{CaCl}_{2}$ alone or in conjunction with an intracellular calcium binding protein. To obtain Factor XIII in the zymogenic form from monocytes and macrophages, as well as from platelets and placenta, it is necessary to disrupt the cells in the presence of a calcium chelator and in the absence of reducing agents. Consequently, it is not surprising that an active transglutaminase was observed in other studies.

It is not possible now to ascertain whether monocytes and macrophages contain one or more than one cytoplasmic transglutaminase. Our results are compatible with the conclusion that these cells contain Factor XIII A chain, which can be activated readily by thrombin-independent pathway(s). In our most carefully prepared samples, this zymogen seems to account for all of the intracellular transglutaminase activity and represents $\sim 0.1 \%$ of the total cellular protein. This is the same concentration that Murtaugh et al. (20) observed for tissue transglutaminase in human monocytes in culture. It is possible that under different conditions different transglutaminase activities may be expressed by the cells. Other work has also suggested that there may be more than one intracellular transglutaminase $(1,40)$, and there is immunochemical evidence for the presence of tissue transglutaminase in macrophages (19). However, the antibody to tissue transglutaminase used by Murtaugh et al. (20) also detected transglutaminase in human platelet extracts. Platelet transglutaminase is chemically and immunochemically identical to the $A$ subunit of plasma Factor XIII (5-7).

In this study transglutaminase activity was not observed in granulocytes. By activity staining lymphocytes were also essentially negative. Very low activity was occasionally observed, which may have been due to the presence of some monocytes in the lymphocyte preparations. We have not been able to demonstrate the presence of $A$ protein in unstimulated lymphocytes.

A specific function for monocyte-macrophage transglutaminase has not yet been determined. One possibility that has received attention involves receptor-mediated phagocytosis (41). $\alpha_{2}$-macroglobulin is known to be a substrate for plasma Factor XIIIa $(42,43)$, and macrophages bind $\alpha_{2}$-macroglobulin-protease complexes (44). Evidence has been presented that ligandreceptor binding and internalization of $\alpha_{2}$-macroglobulin complexes require transglutaminase activity and that inhibitors of Factor XIII block both transglutaminase and endocytosis (45). However, other investigators think that there are no direct data to support a role for transglutaminases in this process (46). Transglutaminase could be active in other macrophage functions. It could, for example, be a source of readily activatable Factor XIII at inflammatory sites for the cross-linking of numerous substrate proteins, including collagen, fibronectin, and fibrinogen-fibrin. Monocytes-macrophages produce other coagulation factors (47-49), and these cells can also function in a manner similar to platelets to provide the membrane surface on which the prothrombinase complex assembles for the generation of thrombin (50). Macrophages can also release fibrinolytic enzymes (51). It is therefore becoming clear that macrophages may constitute an important cellular element in the regulation of hemostasis. Several reactions involved in fibrin formation and degradation require transglutaminasecatalyzed covalent cross-linking. The availability of a macrophage source of Factor XIII in the local microenvironment of clot formation requires further study to determine what role it might have in these reactions.

\section{Acknowledgments}

This research was supported in part by grants HL 29512, CA 29589, and CA 33003 from the National Institutes of Health and by a travel grant from the Swedish Medical Research Council (B82-19R-6183).

\section{References}

1. Folk, J. E. 1980. Transglutaminases. Annu. Rev. Biochem. 49: 517-531.

2. Folk, J. E. 1972. Structure and catalytic properties of hepatic transglutaminase. Ann. NY Acad. Sci. 202:59-76.

3. Lorand, L., L. B. Weissmann, D. Epel, and J. Brunner-Lorand. 1976. Role of the intrinsic transglutaminase in the $\mathrm{Ca}^{2+}$-mediated crosslinking of erythrocyte proteins. Proc. Natl. Acad. Sci. USA. 73: 4479-4481.

4. Brenner, S. C., and F. Wohl. 1978. Human erythrocyte transglutaminase. Purification and properties. Biochim. Biophys. Acta. 522: 74-83.

5. Schwartz, M. L., S. V. Pizzo, R. L. Hill, and P. A. McKee. 1973. Human factor XIII from plasma and platelets: molecular weights, subunit structure, proteolytic activation and crosslinking of fibrinogen and fibrin. J. Biol. Chem. 248:1395-1407.

6. Kiesselbach, T. H., and R. H. Wagner. 1972. Demonstration of factor XIII in human megakaryocytes by a fluorescent antibody technique. Ann. NY Acad. Sci. 202:318-328.

7. Chung, S. I. 1972. Comparative studies on tissue transglutaminase and factor XIII. Ann. NY Acad. Sci. 202:240-255.

8. Lorand, L., T. Urayama, J. W. C. deKiewiet, and H. L. Nossel. 1969. Diagnostic and genetic studies of fibrin stabilizing factor with a new assay based on amine incorporation. J. Clin. Invest. 48:10541064.

9. Lorand, L., K. Campbell-Wilkes, and L. Cooperstein. 1972. A filter paper assay for transamidating enzymes using radioactive amine substrates. Anal. Biochem. 50:623-631.

10. Curtis, C. G., K. L. Brown, R. B. Credo, R. A. Domanik, A. Gray, P. Stenberg, and L. Lorand. 1974. Calcium-dependent unmasking of active-center cysteine during activation of fibrin stabilizing factor. Biochemistry. 13:3774-3780.

11. Credo, R. B., C. G. Curtis, and L. Lorand. 1978. $\mathrm{Ca}^{2+}$-related regulatory function of fibrinogen. Proc. Natl. Acad. Sci. USA. 75: 4234-4237.

12. Henriksson, P., and J. McDonagh. 1983. Factor XIII activation and interactions. In Factor XIII and Fibronectin. R. Egbring and H. G. Klingemann, editors. Medizinische Verlagsgesellschaft mbH, Marburg/Lahn, Federal Republic of Germany. 1-14.

13. Curtis, C. G., T. J. Janus, R. B. Credo, and L. Lorand. 1983. Regulation of factor XIIIa generation by fibrinogen. Ann. NY Acad. Sci. 408:567-576.

14. Stenberg, P., and J. Stenflo. 1979. A rapid and specific fluorescent activity staining procedure for transamidating enzymes. Anal. Biochem. 93:445-452. 
15. Lorand, L., G. E. Siefring, Jr., Y. S. Tong, J. Brunner-Lorand, and A. J. Gray, Jr. 1979. Dansylcadaverine specific staining for transamidating enzymes. Anal. Biochem. 93:453-458.

16. Novogrodsky, A., S. Quittner, A. L. Rubin, and K. H. Stenzel. 1978. Transglutaminase activity in human lymphocytes: early activation by phytomitogens. Proc. Natl. Acad. Sci. USA. 75:1157-1161.

17. Schroff, G., C. Neumann, and C. Sorg. 1982. Transglutaminase as a marker for subsets of murine macrophages. Eur. J. Immunol. 11: 637-642.

18. Kannagi, R., K. Teshigawara, N. Noro, and T. Masuda. 1982. Transglutaminase activity during the differentiation of macrophages. Biochem. Biophys. Res. Commun. 105:164-171.

19. Murtaugh, M. P., K. Mehta, J. Johnson, M. Myers, R. L. Juliano, and P. J. A. Davies. 1983. Induction of tissue transglutaminase in mouse peritoneal macrophages. J. Biol. Chem. 258:11074-11081.

20. Murtaugh, M. P., W. P. Arend, and P. J. Davies. 1984. Induction of tissue transglutaminase in human peripheral blood monocytes. J. Exp. Med. 159:114-125.

21. Boyum, A. 1968. Isolation of mononuclear cells and granulocytes from human blood. Scand. J. Clin. Lab. Invest. 21(Suppl. 97):77-83.

22. Musson, R. A., and P. M. Henson. 1979. Humoral and formed elements of blood modulate the response of peripheral blood monocytes. I. Plasma and serum inhibit and platelets enhance monocyte adherence. J. Immunol. 122:2026-2031.

23. Yam, L. T., C. Y. Lee, and W. H. Crosby. 1971. Cytochemical identification of monocytes and granulocytes. Am. J. Clin. Pathol. 55: 283-290.

24. Rider, D. M., and J. McDonagh. 1981. Resistance of factor XIII to degradation or activation by plasmin. Biochim. Biophys. Acta. 675:171-177.

25. McDonagh, J., W. J. Waggoner, E. J. Hamilton, B. Hindenach, and R. P. McDonagh. 1976. Affinity chromatography of human plasma and platelet factor XIII on organomercurial agarose. Biochim. Biophys. Acta. 446:345-357.

26. Kennet, R. H. 1980. Cloning of hybridomas-Cloning in semisolid agarose. In Hybridomas: A New Dimension in Biological Analysis. R. H. Kennet, T. J. McKearn, and K. B. Bechtol, editors. Plenum Publishing Corp., New York. 372-373.

27. Towbin, H., T. Staehelin, and J. Gordon. 1979. Electrophoretic transfer of protein from polyacrylamide gels to nitrocellulose sheets: procedure and application. Proc. Natl. Acad. Sci. USA. 76:4350-4354.

28. Johnson, D. E., and J. H. Elder. 1983. Antibody directed to determinants of a Maloney virus derived MCF GP 70 recognizes a thymic differentiation antigen. J. Exp. Med. 159:1751-1756.

29. Laemmli, U. K. 1970. Cleavage of structural proteins during assembly of the head of bacteriophage $\mathrm{T}_{4}$. Nature (Lond.). 227:680685.

30. Ganrot, P. O. 1972. Crossed immunoelectrophoresis. Scand. J. Clin. Lab. Invest. 29(Suppl. 124):39-41.

31. Ikematsu, S., R. P. McDonagh, H. M. Reisner, C. Skrzynia, and J. McDonagh. 1981. Immunochemical studies of human factor XIII: radioimmunoassay for the carrier subunit of the zymogen. $J$. Lab. Clin. Med. 97:662-671.

32. Skrzynia, C., H. M. Reisner, and J. McDonagh. 1982. Characterization of the catalytic subunit of factor XIII by radioimmunoassay. Blood. 60:1089-1095.

33. Mason, T. E., R. F. Phifer, S. S. Spicer, R. A. Swallow, and R. B. Dreskin. 1969. An immunoglobulin-enzyme bridge mechanism for localizing tissue antigens. J. Histochem. Cytochem. 17:563-569.
34. Becker, S., and S. Haskill. 1980. Characterization of the presumptive sarcoma cells in primary MSV tumors. Int. J. Cancer. 25:543-550.

35. McDonagh, J., H. Messel, R. P. McDonagh, G. Murano, and B. Blombäck. 1972. Molecular weight analysis of fibrinogen and fibrin chains by an improved sodium dodecyl sulfate gel electrophoresis method. Biochim. Biophys. Acta. 257:135-142.

36. Swigert, S., J. L. Koppel, and J. H. Olwin. 1963. Selective inactivation of fibrin stabilizing factor contaminant in fibrinogen. Nature (Lond.). 198:797-798.

37. Kaminski, M., and J. McDonagh. 1983. Studies on the mechanism of thrombin interaction with fibrin. J. Biol. Chem. 258:1053010535.

38. McDonagh, R. P., J. McDonagh, and B. Blombäck. 1972. Isolation and characterization of the S-carboxymethyl derivatives of crosslinked and non-crosslinked human fibrin. Proc. Natl. Acad. Sci. USA. 69:3648-3652.

39. Colvin, R., G. Lynch, J. McDonagh, M. Erikson, J. Karnick, K. Power, and R. Cradin. 1985. Factor XIII A subunit is synthesized and expressed by macrophages. Fed. Proc. 44:906.

40. Lorand, L., and S. M. Conrad. 1984. Transglutaminases. Mol. Cell. Biochem. 58:9-35.

41. Davies, P. J., and M. P. Murtaugh. 1984. Transglutaminase and receptor-mediated endocytosis in macrophages and cultured fibroblasts. Mol. Cell. Biochem. 58:69-77.

42. Mosher, D. F. 1976. Action of fibrin stabilizing factor on coldinsoluble globulin and $\alpha_{2}$-macroglobulin in clotting plasma. J. Biol. Chem. 251:1639-1645.

43. Sottrup-Jensen, L., T. M. Stepanik, D. M. Wierzbicki, C. M. Jones, P. B. Lonblad, T. Kristensen, S. B. Mortensen, T. E. Petersen, and S. Magnusson. 1983. The primary structure of $\alpha_{2}$-macroglobulin and localization of a factor XIIIa crosslinking site. Ann. NY Acad. Sci. 421:41-60.

44. Kaplan, J., and M. L. Nielsen. 1979. Analysis of macrophage surface receptors. I. Binding of $\alpha_{2}$-macroglobulin-protease complexes to rabbit alveolar macrophages. J. Biol. Chem. 253:7323-7328.

45. Davies, P. J. A., D. R. Davies, A. Levitzki, F. R. Maxfield, P. Milhaud, M. C. Willingham, and I. H. Pastan. 1980. Transglutaminase is essential in receptor-mediated endocytosis of $\alpha_{2}$-macroglobulin and polypeptide hormones. Nature (Lond.). 283:162-167.

46. Tycko, B., M. DiPaola, D. J. Yamashiro, S. Fluss, and F. R. Maxfield. 1983. Acidification of endocytic vesicles and the intracellular pathways of ligands and receptors. Ann. NY Acad. Sci. 421:424-433.

47. Osterud, B., U. Lindahl, and R. Seljelid. 1980. Macrophages produce blood coagulation factors. FEBS (Fed. Eur. Biochem. Soc.) Lett. 120:41-43.

48. Schwartz, B. S., G. A. Levy, D. S. Fair, and T. S. Edgington. 1982. Murine lymphoid procoagulant activity induced by bacterial lipopolysaccharide and immune complexes is a monocyte prothrombinase. J. Exp. Med. 155:1464-1479.

49. Ewan, V. A., R. L. Edwards, and F. R. Rickles. 1983. Expression of procoagulant activity in a human monocyte-like cell line. J. Lab. Clin. Med. 101:401-410.

50. Tracy, P. B., M. S. Rohrbach, and K. G. Mann. 1983. Functional prothrombinase complex assembly on isolated monocytes and lymphocytes. J. Biol. Chem. 258:7264-7267.

51. Sherman, L. A., J. L. Lee, and C. C. Stewart. 1981. Release of fibrinolytic enzymes by macrophages in response to soluble fibrin. $J$. Reticuloendothel. Soc. 30:317-329. 